THE APPLICATION OF FRACTURE MECHANICS TO THE INVESTIGATION OF CRACKING IN MASSIVE CONCRETE CONSTRUCTION ELEMENTS OF DAMS

A. A. Khrapkov, L. P. Trapesnikov, G. S. Geinats, V. I. Pashchenko and A. P. Pak*

\title{
INTRODUCTION
}

The paper describes experimental and theoretical investigations undertaken at the VNIIG on the applicability of the Griffith-Irwin theory to thermal crack history in massive concrete elements of dams.

\section{EXPERIMENTAL INVESTIGATIONS}

The KIC values taken to characterize plane-strain fracture toughness of concrete were determined on concrete specimens with notches. For concrete of specific composition ${ }^{1}$ age-dependent values of $K_{I C}$ were established and correlated with values of tension strength $\sigma_{\text {rupt }}$ (Table 1 ).

The $\mathrm{K}_{\mathrm{IC}}$ values depend upon age in the same way as the modulus of elastic instantaneous strains or strength, they were very close to the dependence of $K_{I C}$ on $t$ established by Naus and Lott [1]. Estimations analogous to those performed by Kaplan [2] indicated that the strain energy release at concrete fracture was mostly spent on microcracking and to a lesser extent on the formation of a macrocrack in previously "loosened" material. ext general it means that effective surface energy, $\gamma$, is not a material constant as is the related value of $K$. It depends on the development of the "pseudoplastic" strain a wich This may be responsible for the fact that the KIC value is lower at unstable Phis ay be respon For example, concrete $\mathrm{e}^{2}$ tested at an age of 150 days yields

$K_{I C} \simeq 0.75 \div 0.85 \mathrm{MPa} \cdot \mathrm{m}^{1 / 2}$ in the first case and $K_{I C} \simeq 1.90 \mathrm{MPa} \cdot \mathrm{m}^{1 / 2}$ in the second one.

Data on KIC available in the literature were obtained either for cementsand concrete or concrete with aggregate of maximum size $20-30 \mathrm{~mm}$. Studies on how these data can be applied to hydraulic concrete, i.e. to concrete with aggregate of maximum size from 80 to $150 \mathrm{~mm}$, are of great practical significance. Table 2 gives the results of testing concrete

1. The $1: 2.2: 4.3$ concrete (by weight) with portland cement of 400 grade had the water-cement ratio 0.50. The maximum size of a crushed stone coarse aggregate was $20 \mathrm{~mm}$. The tested specimens were cylinders of $0.15 \mathrm{~m}$ diameter and $0.10 \mathrm{~m}$ height with a vertical notch in a plane of compressive forces. Each point represented average of 3 - 8 tests.

2. The $1: 2.7: 4.6$ concrete (by weight) with portland cement of 400 grade had the water-cement ratio 0.45 . The maximum size of a crushed stone coarse aggregate was $30 \mathrm{~mm}$. The $1.3 \times 0.5 \times 0.2 \mathrm{~m}$ specimens with a notch at the center of the longer edge were tested under central extension and eccentric compression.

* The B. E. Vedeneev All-Union Research Institute of Hydraulic Engineering, (VNIIG), Leningrad, U.S.S.R. 
specimens at 90 days with a river gravel coarse aggregate of maximum size 30 and $40 \mathrm{~mm}^{3}$. Experiments show that $K_{\text {IC }}$ increases with

the

SOLUTION OF THERMOELASTIC AND ELASTIC PROBLEMS FOR STRIPS, SLABS AND BEAMS WITH NOTCHES

Wal1 - or slab-type concrete structural elements are widely used in hydraulic Wall- or slab-type concrete structural elem, buttress and lock walls, spillway piers, engineering (concrete dam crests, when the $K_{\text {TC }}$ values for concrete are known downstream apron slabs, etc.). When the $K_{\text {IC }}$ values the above structural the calculation or temperature crack propagation in the above structural elements is reduced to solth fixed cracks (notches).

The considered are concerned with cracks on one or The thermoelastic problems considered are concerned with cracks on one two sides of a constructional e lement, with surface and internal cracks at all possible spacings, including the extreme cases: a single crack and complete fracture of concrete in the destruction zone. Consideration is given to both "free" walls and slabs with zero principal vector and moment of stresses at each cross section and "restrain displacements in some cross sections normal to the surfaces equal zero.

In conformity with recently developed techniques [3 - 5], the solution of problems of thermoelasticity for slabs $-y_{0} \leq y \leq y_{0}$ is reduced to solvin the Fredholm equations of the first kind, the kernels of the equations and diagrams of dimensionless factors of

$$
\frac{K_{I}{ }^{(i)}(1-\nu)}{E \alpha \sqrt{y_{0}} \sqrt{2 \pi}}
$$

For the basic temperature fields in the form of a succession of Legendre for the basic temperature fien $\alpha$ is the coefficient of linear expansion of

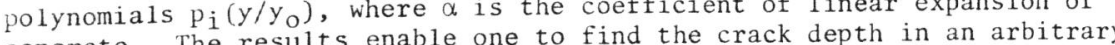
concrete. The results enabin terms of the one-dimensional temperature field, described cryek $t$. The tables and above mentioned orth

$$
\frac{K_{I}{ }^{(i)}(1-\nu)}{E \alpha \sqrt{y_{O}} \sqrt{2 \pi}}
$$

For the surface cracks in "free" slabs are presented in $[4,5]$. Figure 1 illustrates the values of these factors for a "free" slab (wali) with a ingle surface crack. In practice crack growth is frequently determined not only by temperatures but also by forces, it should be noted that due to non-linearity of the problem both factors must be considered simultaneously. So the problems of the isothermal theory of elasticity for notched slabs and beams under bending, central extension, eccentric compression, hydrostatic pressure in joints, etc. were also analyzed. Som [3].

3. Cylinders of diameter $0.4 \mathrm{~m}$ and 1 ength $0.4 \mathrm{~m}$ with a vertical notch in a plane of compressive forces were tested. Each point represents a plane of compressive forc
THE PRACTICAL APPLICATION OF THEORETICAL AND EXPERIMENTAL DATA

Theoretical and experimental results were applied to various practical problems, first to determining the depth of the crack or set of cracks which forms in a plain concrete wall in a one-dimensional temperature field. Effects of the wall thickness, heat insulation, the kind of crack (on one or two sides of a wall), air temperature variation amplitude an dead load contribution, etc. on the kinetics and depth of cracks were studied. An example of the analysis is given in Figure 2, a diagram of depth variation of a crack in a concrete wall with a notch of the depth $a_{0}$ in the process of getting colder. $\mathrm{K}_{\mathrm{IC}}$ is assumed to be independent of a.

The stress analysis of crests of a number of concrete dams (the Ust-IIim dam on the Angara River, the Toktogul dam on the Naryn River) with due regard for horizontal and vertical joints opened on the upstream and downstream faces were performed in such a way.

Another procedure, also based on ideas of brittle fracture mechanics was developed for the stress analysis of lower, massive parts of dams which cannot be calculated as a wall or a strip. This procedure is discussed below.

\section{OPENING OF HORIZONTAL JOINTS ON A DOWNSTREAM FACE OF A DAM}

The stresses in concrete dams which are in operation in regions with severe climate are profoundly affected by variation in temperature of the ambient air. In winter low air temperatures produce tensile stresses exceeding those of compression due to hydrostatic pressure and the dead weight of the structure. The fact is confirmed by field observations of we the hydrostan temperathe hydrostatic

The variations in ambient air temperatures on the downstream face during year are approximated by:

$$
T=T_{0} \cos 2 \pi \omega t,
$$

where $T_{0}$ is the amplitude dependent on a dam location and $\omega$ is the variatio frequency equal to $0.0317 \mu \mathrm{Hz}$. These inside the dam have the form of:

$$
T(x, y, t)=T^{(c)}(x, y) \cos 2 \pi \omega t+T^{(s)}(x, y) \sin 2 \pi \omega t,
$$

where $T^{(c)}(x, y)$ and $T^{(S)}(x, y)$ are functions estimated by solving the problem of thermal conductivity.

A temperature field (2) in a dam is assumed to contain no cracks induces stresses $\sigma_{x}, \sigma_{y}, \tau_{x y}$ of the form:

$$
\sigma_{x}(x, y, t)=\sigma_{x}^{(c)}(x, y) \cos 2 \pi \omega t+\sigma_{x}^{(s)}(x, y) \sin 2 \pi \omega t .
$$

The terms with superscripts $\mathrm{c}$ and $\mathrm{s}$ are obtained by solving the twodimensional static problem of the theory of elasticity for a dam with temperature fields $T(c)(x, y)$ and $T(s)(x, y)$, respectively. Temperature and 
the stress distribution to be readily established for any month of the year.

The crack depth on the downstream face is calculated on the assumption that the $K_{I}$ value is limited by the value of $K_{I C}$ on crack extension. Due to the probability of many repeated openings of cracks the effective energy of fracture and the stress intensity factor in the region of the crack tip are taken as zero.

To find the crack depth a in the horizontal cross-section under consideration the total coordinate system thus:

$$
\sigma_{y}=\sum_{i=0}^{m} B_{i} x^{i}, \quad \tau_{x y}=\sum_{i=0}^{m} c_{i} x^{i} .
$$

Since a number of horizontal cracks occurs (or all the construction joint open) on the downstream face the stress intensity factors are evaluated for a periodic system of cracks. The value of $K_{I}$ can be written as follows

$$
\begin{aligned}
& K_{I}(a)=\sum_{i=0}^{m}\left[B_{i} R_{11}^{(i)}(s / a)+c_{i} R_{12}^{(i)}(s / a)\right] a^{i+1 / 2}, \\
& R_{11}^{(i)}(s / a)=n_{11}^{(i)} \phi_{i}(s / a), \quad R_{12}^{(i)}(s / a) n_{12}^{(i)},
\end{aligned}
$$

where $s$ is the crack spacing; $n_{11}^{(i)}, n_{12}^{(i)}$ are the stress intensity factors for a single crack of depth $a=1$ propagating at an angle $\theta$ to the face of the dam when the loads on the crack contour are $\sigma_{y}=x^{i}$, to the face $\sigma_{y}=0, \tau_{x y}=x^{i}, \phi_{i}(\mathrm{~s} / \mathrm{a})$ are the functions taking the periodic pattern $\sigma_{y}=0, \tau_{x y}=x^{1}, \phi_{i}(s / a)$
of cracks into account.

The values of $n_{11}^{(i)}, n_{12}^{(i)}$ are derived according to [6]. The functions i (s/a) are assumed to be similar to those derived for periodic cracks normal to the boundary [7], their spacing coinciding with that of inclined cracks soll so they are taken to be the

Figure 3 shows normal stresses over horizontal cross sections of the downstream and upstream faces of gravity dams as well as diagrams of variation in crack depth during a year.

Cracking of the downstream face of a dam gives a decrease in the compressive stresses (or an increase in tensile stresses) due to hydrostatic presure and dead weight, as well as in tensile thermal stresses, as against the same stresses in a monolithic dam. The total effect is determined by the mean monthly temperature amplitude, the downstream face slope, the cross-section position over the dam height and other factors. According to calculations performed for existing dams with the opening of crack considered, the total tensile stresses at the upstream face within the midale part of the height of the Ust-IIim dam decrease during winter (Figure 3a), while the compressive stresses at the upstream face of the Krasnoyarsk dan (Figure $3 b$ ) increase, the amplitude of stress variation being $\sim 0.4$ to $0.6 \mathrm{MPa}$ in the cross-section analysed during a year.
As a rule, cracks open in November-December and close in March-April. Thermal stresses are found to achieve maximum values just at the moment of crack closing. The longest horizontal cracks occur in the middle portion of a dam in January-February.

Thus, the application of fracture mechanis to concrete permits the analysis of massive concrete dams in operation in cold regions, regarding the processes associated with ambient air temperature variations, as well as

making it possible to consider more completely the factors affecting dams at the design stage.

REFERENCES

1. NAUS, D. I. and LOTT, J. L., J. Amer. Concr. Inst., 66, 1969, 481. 2. KAPLAN, M. F., J. Amer. Concr. Inst., 58, 1961, 591.

3. PASHCHENKO, V. I. and TRAPESNIKOV, L. P., Izvestia VNIIG, 101, 1973 , 17.

4. PASHCHENKO, V. I. and TRAPESNIKOV, L. P., Izvestia VNIIG, 105, 1974

5. PASHCHENKO, V. I. and TRAPESNIKOV, L. P., Izvestia VNIIG, 108, 1975,

6. KHRAPKOV, A. A., Int. J. of Fract. Mech., 7, 1971, 373.

7. KHRAPKOV, A. A. and GEINATS, G. S., Izvestía VNIIG, 93, 1970, 6.
Table 1

\begin{tabular}{|l|ccccc|}
\hline \multirow{2}{*}{$\begin{array}{l}\text { Criteria of } \\
\text { Concrete }\end{array}$} & \multicolumn{5}{|c|}{ Test Age, Days } \\
\cline { 2 - 6 } & $j$ & 7 & 14 & 28 & 90 \\
\hline $\mathrm{K}_{\mathrm{IC}}, \mathrm{MPa} \cdot \mathrm{m}^{1 / 2}$ & 0.152 & 0.219 & 0.440 & 0.491 & 0.609 \\
$\sigma_{\text {rupt }}, \mathrm{MPa}$ & 0.64 & 1.08 & 1.52 & 1.86 & 2.70 \\
\hline
\end{tabular}

Table 2

\begin{tabular}{|l|ccc|}
\hline \multirow{2}{*}{$\begin{array}{l}\text { Criterion } \\
\text { of Concrete }\end{array}$} & \multicolumn{3}{|c|}{ Maximum Size of Aggregate, mm } \\
\cline { 2 - 4 } & 20 & 30 & 40 \\
\hline $\mathrm{K}_{\mathrm{IC}}, \mathrm{MPa} \cdot \mathrm{m}^{1 / 2}$ & 0.563 & 0.946 & 1.005 \\
\hline
\end{tabular}




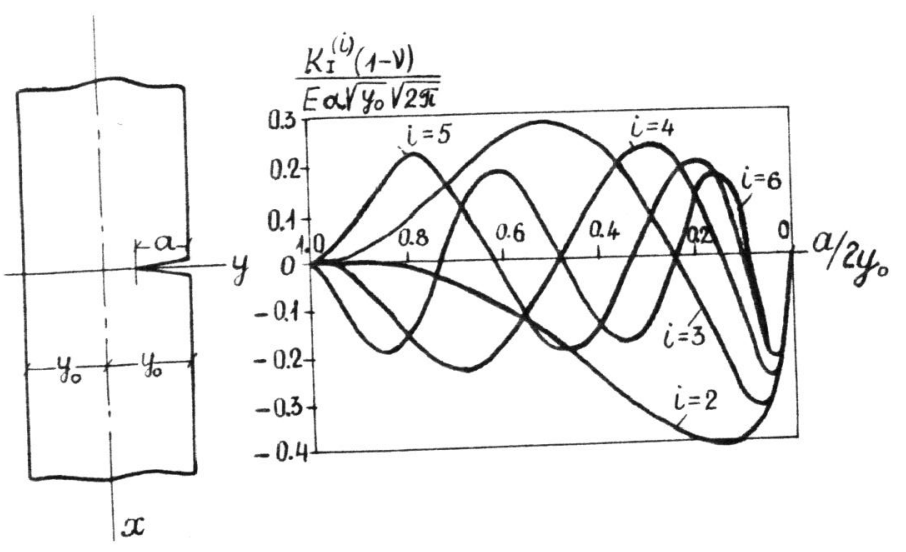

of Dimensionless Factors of Stress Intensity (i) $(1-v) / E a \sqrt{y_{0}} \sqrt{2 \pi}$ for the Basic Temperature Fields in $\mathrm{K}_{\mathrm{I}}(1-v) / \mathrm{\alpha} \sqrt{y_{0}}$ the Form of a successing a Single Surface Crack

(A "Free" Infinite Strip with a Single Surface Crack)

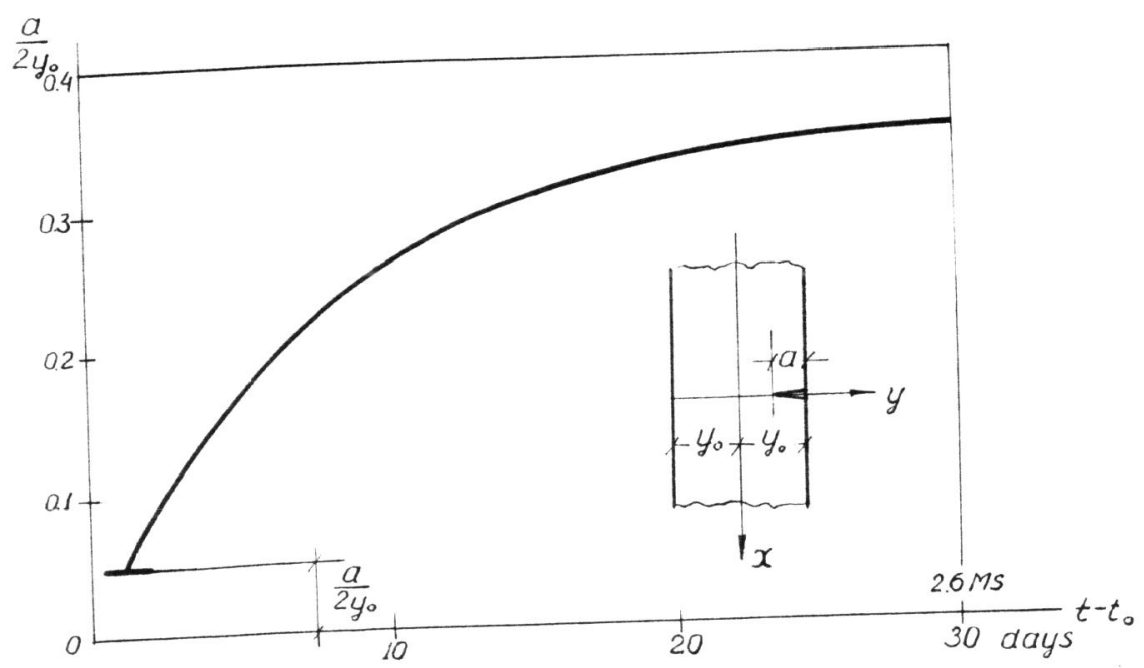

. - $y_{0} \leq y_{0}$ with an Initial Notch $a_{0} / 2 y_{0}=0.05$, put at the $y_{0}-$ - $y_{0}$ into the Medium with the Temperature $\mathrm{T}_{\mathrm{A}}$; $2 \mathrm{y}_{\mathrm{O}}$ remperatur $10 \mathrm{~m}$, and the Coefficient of Thermal Conductivity being Equal $10^{-6} \mathrm{~m}^{2} / \mathrm{s} ; \mathrm{K}_{\mathrm{IC}}(1-\nu) / \mathrm{E}_{\alpha}\left(\mathrm{T}_{\mathrm{O}}-\mathrm{T}_{\mathrm{A}}\right) \sqrt{y_{O}}=0.227$

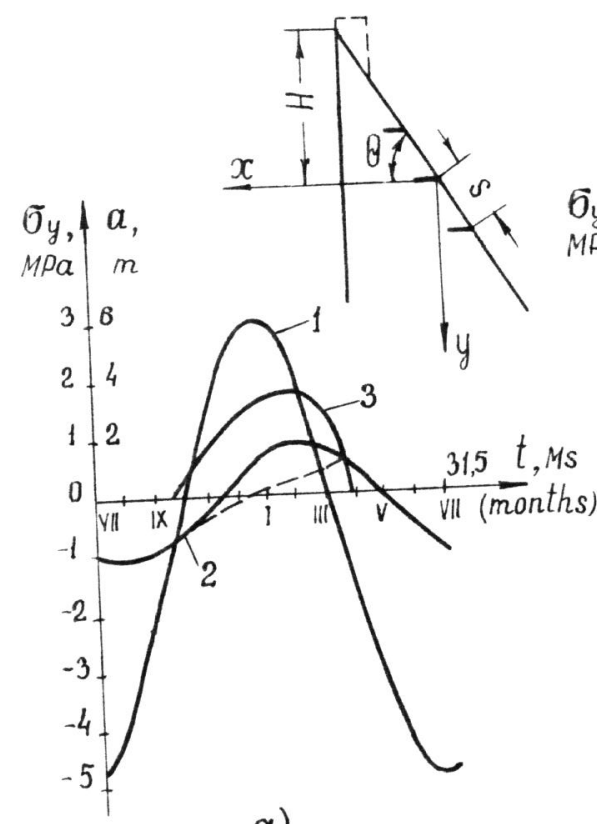

a)

$\sigma_{y}, a$

3. 6

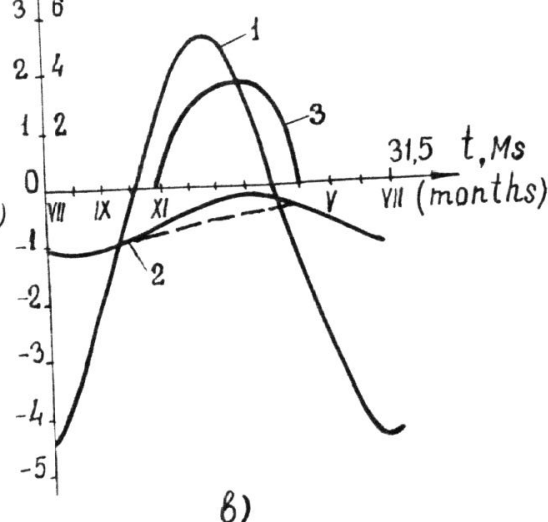

b) Opened in Horizontal Cross-Sections of

T) The Ust-IIim Dam $\left(\mathrm{H}=48 \mathrm{~m}, \theta=55^{\circ}, \mathrm{E \alpha}\right.$.

a) The

The $2400 \mathrm{~kg} / \mathrm{m}^{3}$ ).

the curves show

2 - stresses $\sigma_{y}$ at the upstream face (the of cracks taken

ration

3 - crack depth on the downstream face 